\title{
A Comparison of Three Payment Systems For Public Paediatric Dental Services
}

JENNIFER HANTHORN CONQUEST, JOHN SKINNER, ESTIE KRUGER, MARC TENNANT

Jennifer Hanthorn Conquest -University of Western Australia School of Anatomy Physiology and Human Biology, School of Human Sciences, 35 Stirling Highway, Crawley, Western Australia 6009, Australia

John Skinner - Centre for Oral Health Strategy New South Wales, Wentworthville, New South Wales 2145, Australia

Estie Kruger, Marc Tennant - University of Western Australia, International Research Collaborative, Oral Health and Equity, School of Anatomy, Physiology and Human Biology, Perth 6009, Western Australia, Australia

Correspondence: h.black@westernsydney.edu.au

\section{Abstract}

Objective This study investigated the delivery of paediatric (0-17 years) government dental services in New South Wales (NSW), Australia through public dental clinics and the commissioned payments models of Fee-forService and Capped-Fee.

Method De-identified patient data from government provided dental care and the commissioned services was sourced from NSW Oral Health Data Warehouse for evaluation and interpretation using descriptive analysis during the period 1 January 2012 to 31 December 2013.

Result The breakdown of dental care provided the associated cost analysis for the study's cohort that resulted in both years, more than 50 percent dental services offered to paediatric patients were preventive care in all payment systems. The most common preventive items offered were fluoride treatment, dietary advice, oral health education and fissure sealants.

Conclusion There was little difference in the mix of dental care provided between study years and age groups through the three payment systems in NSW. The difference between the government services and those provided via the Fee-for-Service and Capitation payment systems was negligible.

This has important implications for the delivery of dental care to public dental care, particularly when patients may not live close to a public dental clinic and also with the interest nationally in giving patients greater choice.

Keywords Paediatric, Payment models, Oral health 


\section{INTRODUCTION}

Australia has always relied on a mix of State Government, Commonwealth Government, and private funding to finance the delivery of healthcare services. Medicare, a Commonwealth funded system, provides free or subsidised treatment by doctors, specialists, optometrists, and in a very narrow range of specific circumstances, dentists and other allied health practitioners. In many cases, individuals are expected to contribute via a copayment where bulk-billing is not offered. Bulk-billing is the practice among health professionals of choosing to be paid reduced fees directly by the government, rather than bill patients fully and bear the cost of billing.

Dentistry operates through quite a different model. The majority of dental care is funded by the individual in a user pay, free-market system, with costs often off-set via private health insurance. For those without the means to access private dental services, a safety-net public dental service is provided by State and Territory (State) Governments.

In New South Wales (NSW), the State with the largest population in Australia, the NSW Government provides free dental care to all children and adolescents $132 \%$ of total population). [1]

To address the dental needs of these children and adolescents, the public dental services are provided by fifteen Local Health Districts, through a mix of clinicians, including dentists, oral health therapists, dental hygienists and dental prosthetists. [1,2] The Government service is provided, in part, by Government clinics located in hospitals, schools, community health facilities, or mobile dental clinics. In addition, services are also provided to public dental patients via a voucher (Fee-for-Service) system using private dentists. Similar vouchers systems are used for public dental patients in other countries. [1] There are several payment systems used by the NSW Government, through which eligible patients, including the young and the disadvantaged, can receive free public dental care. [1,2]

The initial access point for a child and adolescent to receive free dental care during this study, and currently across NSW, is through the Government service telephone triage process that prioritises those most in need based on self-reported symptoms and socio-demographic risk factors. Thus, all public dental services in NSW are funded under one of three payment systems: A fee-for-servicescheme (FFSS) provided by private practitioners (dentists); a Capped-Fee capitation payment scheme (CPS) provided by final year oral health therapy students; and a free Public Dental Service (PDS) provided by Government oral health therapists in government clinics.

\section{The Three Payment Systems}

Three payment systems for public dental services were compared.

The first payment system is the public dental service (PDS) In-house provision of care within public dental clinics. It offers paediatric general dental services, such as examinations, restorations, and dentures, with restricted specialist services and outreach specialist services to rural and remote areas. [1] The paediatric general in-house services under the PDS were mainly provided by oral health therapists.

Local Health Districts in NSW also procure private practice services from dentists through a contracted Fee-for-Service model, particularly when demand is high or additional Commonwealth funding is available. This FeeFor-Service-Scheme (FFSS) payment system offers emergency, general, and denture vouchers that can be used with private dental 
practitioners registered under the NSW Oral Health Fee for Service Scheme. [1] This is an alternative service delivery model for all NSW Local Health Districts. Under the FFSS a limit is set based on the Department of Veterans Affairs Schedule of fees. [1] The FFSS payment system is funded by the Government to external private practices based on set fees for each the item of care provided. [4]

A Capped-Fee capital payment system (CPS) was introduced in 2011, in the former Greater Southern Area Health Service in NSW. This payment system subsidised an educational institution to use Bachelor of Oral Health students $(\mathrm{BOH})$ to deliver dental care to child Government service patients. [1] The CPS offers diagnostic courses of care for: (i) active caries and pain; (ii) active caries and no pain; and (iii) no active caries and no pain. These services are provided to children under 18 years, in the following age bands: aged 0-5 years, 6-11 years and 12-17 years. The CPS payment limits for these diagnostic courses of care and age bands were based upon the underlying caries status of the NSW child population presented in the 2007 Child Dental Survey. [1] The CPS payment system offered one annual, full course of care for child patients, treated by $\mathrm{BOH}$ students under direct supervision.

Therefore, the study was conducted to determine if the mix of dental treatment items of care, provided through the three payment systems, by the different practitioner types, were influenced by the payment system used to treat patients.

The study was completed under ethics approval from The University of Western Australia (RA/4/1/5606) and the Greater Western Area Health Service Human Research
Ethics Committee (HREC/13/GWAHS/25). These organisations comply with the Declaration of Helsinki. Both organisations granted a 'waiver' to the requirement for verbal or written consent for the analyses in this study.

\section{METHODS}

The study included the analyses of 0 to 17 year-old de-identified patient record data obtained from NSW Health Oral Health data warehouse a two-year period (1 January 2012 to 31 December 2013).

This study is largely descriptive and the use of non-parametric tests to determine significant differences between the three payment systems would not add value to the findings.

The children and adolescents treated through both the PDS and FFSS payment systems were distributed across NSW, whilst the children who received care through the CPS payment system, where located in the former Greater Southern Area Health Service.

\section{Databases}

NSW has eight individual oral health databases that record patient demographics, dental treatment provided, type of course of care, and the practitioners details for services provided to public dental patients. The databases include all three funding models; PDS, FFSS, and CPS. Patient data for the PDS are recorded by the treating practitioner. The patient data for FFSS and CPS payment systems are captured through the paper-based voucher process. The voucher is completed by the treating practitioner/student and signed by the child's parent or carer, confirming the treatment provided. The patient's treatment, identified on the voucher, is entered into the appropriate database by an authorised public servant. 


\section{Service Item Data}

All item of care numbers and definitions in this study are derived from the Australian Schedule of Dental Services Glossary 9th edition. [1]

All analysis was completed using Version 13 Microsoft Excel.

\section{RESULTS}

The treatment item numbers used in the analysis were categorised into dental service groupings, consistent with previous studies, using the definitions identified in the Schedule (Table 1). All items provided in the calendar years 2012 and 2013, under the three funding models for the entire State of NSW, were included in the study.

A total of 600,395 (2012) and 665,707 (2013) items of treatment were delivered during the study period. Of these, the combined total for 2012 - 2013 was: (i) 1,409 for the CPS, (ii) FFSS 5,870, and (iii) PDS 1,257,387 (Table 2). Approximately half of the children in each year were aged 6 - 11 years of age (Table 2). In 2012 , it was noted that the proportion of $6-11$ years of age accessing the FFSS and the CPS was higher than in the PDS, and was also higher than in 2013, although the total number of cases were relatively small.

\begin{tabular}{|c|c|c|c|c|c|c|c|c|c|}
\hline \multirow[b]{2}{*}{ Category } & \multirow[b]{2}{*}{ Description ofItems } & \multicolumn{4}{|c|}{2012} & \multicolumn{4}{|c|}{2013} \\
\hline & & $\begin{array}{l}\text { GOVT Item } \\
\text { Number }\end{array}$ & Rank & CAP Rank & FFS Rank & $\begin{array}{l}\text { GOVT Item } \\
\text { Number }\end{array}$ & Rank & CAP Rank & FFS Rank \\
\hline Preventive & Oral hygiene edvcation & 141 & 1 & 3 & 3 & 141 & 1 & 3 & 3 \\
\hline Diagnostic & Comprehensive oral examination & 11 & 2 & 2 & 2 & 123 & 3 & 2 & 2 \\
\hline Preventive & Concentrated remineralisation -1 tooth & 123 & 3 & & & 11 & 2 & 7 & 7 \\
\hline Preventive & Fissure and or tooth surface sealing & 161 & 4 & 1 & 1 & 161 & 4 & 1 & 1 \\
\hline Preventive & Dietary advios & 131 & 5 & 4 & 5 & 131 & 5 & 4 & 5 \\
\hline Restorative & Achesive posterior restoration -1 surface & 531 & 6 & 5 & 6 & 22 & 7 & 6 & 6 \\
\hline Diagnostic & Intraoral periapical or bitewing radiograph & 22 & 7 & 6 & 7 & 531 & 6 & 5 & 4 \\
\hline Diagnostic & Photographic records - intraoral & 72 & 8 & & & 72 & 8 & & \\
\hline Oral Surgery & Removal of a tooth or part(s) thereof & 311 & 9 & & 9 & 311 & 9 & & \\
\hline Restorative & Achesive posterior restoration -2 surfaces & 532 & 10 & & & 532 & 10 & & 9 \\
\hline Preventive & Removal of plaque and or stain & 111 & 11 & & & 111 & 11 & & \\
\hline Diagnostic & Periodic oral examination & 12 & 12 & & & 12 & 12 & & \\
\hline Preventive & Removal of calculus - first visit & 114 & 13 & & 8 & 14 & 14 & & 8 \\
\hline Diagnostic & Consultation & 14 & 14 & & & 114 & 13 & & \\
\hline Preventive & Topical application of remineralisation -1 treatment & 121 & 15 & & & 121 & 15 & & \\
\hline Diagnostic & Oral examination-limited & 13 & 16 & & & 13 & 16 & & \\
\hline
\end{tabular}

Table 1

\begin{tabular}{|c|c|c|c|c|c|c|}
\hline \multirow{2}{*}{ Age Group } & \multicolumn{3}{|c|}{2012} & \multicolumn{3}{|c|}{2013} \\
\hline & GovT & CAP & FFS & GOVT & CAP & FFS \\
\hline $0-5$ years & 113,696 & 85 & 0 & 120,972 & 105 & 487 \\
\hline $6-11$ years & 269,003 & 579 & 1,704 & 306,025 & 443 & 2,296 \\
\hline 12-17 years & 213,352 & 72 & 468 & 234,339 & 125 & 915 \\
\hline Total & 596,051 & 736 & 2,172 & 661,336 & 673 & 3,698 \\
\hline
\end{tabular}

Table 2 


\section{Overall Mix of Items}

There was little difference in the mix of items provided between study years and age groups (Figure 1). The difference between the PDS provided care and those of the FFSS and CPS was minor. In both study years, preventive services were the highest (over $50 \%$ of all groups of care provided) in all three funding models. The most common preventive items, in the three practitioner types and their associated funded models, were fluoride treatment (123), dietary advice (131), oral health education (141), and fissure sealants (161). In 2012, preventive items provided under the CPS and the FFSS were $15 \%$ and $10 \%$ higher respectively, than that provided under the PDS. The preventive items provided in 2013 through the CPS and the FFSS funded models were both $7 \%$ higher than the PDS. This may have been due to the smaller numbers in the procured models of care in 2012.

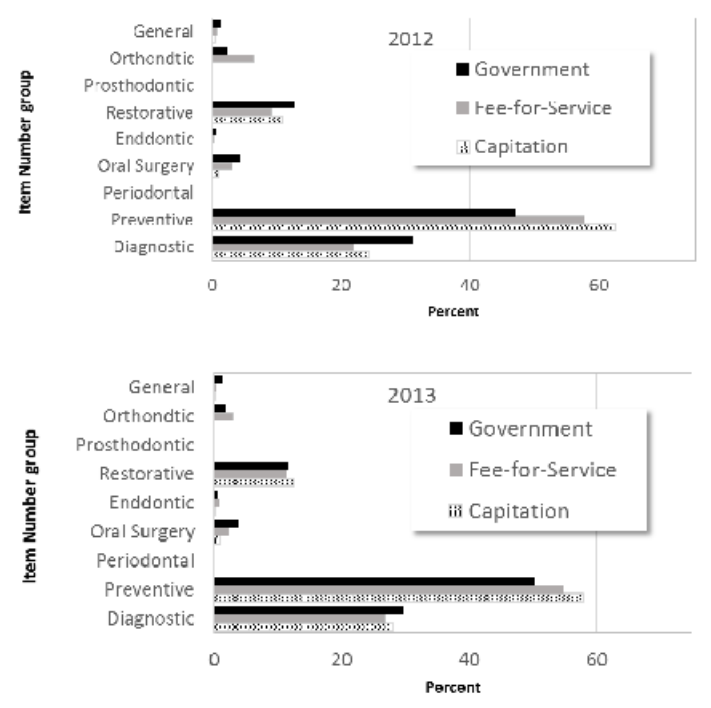

Figure 1

\section{Priority items}

There are in excess of 350 items that could be provided in the full Schedule, although only the most frequently used items of care were included for analysis in this study. The PDS care in $\mathbf{2 0 1 2}$ was used as the comparison. The PDS for 2013 did not differ significantly in the cluster of items provided: a total of 16 items made-up the $85 \%$ of the total care (Table 1 ). One variation was observed with the second ranked item, comprehensive examination (011) and third ranked item, concentrated fluoride application for a single tooth (123), being transposed in 2013. The CPS funded model include 6 items making up the treatment in 2012, which expands to 7 items in 2013, and is consistent with the top 7 items in the baseline 2012 Government service. The items included one surface posterior

restoration (531), radiograph (022) and removal of calculus - first visit (114). Similarly, the FFSS in terms of the mix of items was very close to the baseline. In 2012 there were 8 items, and in 2013 there were 9 items, most being consistent with the top volume items in the baseline PDS provided mix (2012). The difference was the movement of item removal of calculus - first visit (114) from $13^{\text {th }}$ position in the baseline to $7^{\text {th }}$ position in the FFSS funded model (Table 1).

\section{DISCUSSION}

Previous studies compare the types of medical and dental care provided through FFSS and CPS, and salaried government practitioners. $[1,2,3]$ The studies evaluated the impact of funded service models on patient care and professional behaviour. Bradson et al (1998), Lo et al (2002) and others identified that the top two dental service deliveries provided under FFSS and CPS, were diagnostic and preventive services. $[1,2,3]$ Other research has found that there was an increase in the use of fissure and/or tooth surface sealants and a reduction of restorations through CPS). [1] However, in this study, restorations ranked $5^{\text {th }}$ 
in 2012 and $6^{\text {th }}$ in 2013 for both FFSS and CPS funded models, resulting in minimal reduction (Table 1).

This study supports the findings of Holloway et al (1990) and has shown that there is no evidence of major variations of the dental item mix provided through each of the funded models. [16] The study's results clearly show that preventive treatment remains the predominant care provided (over $50 \%$ of all care), irrespective of the payment system, for both 2012 and 2013.

The results of this study indicated that the mix of items of care provided did not differ in either of the two externally procured payment systems (CPS and FFSS) when compared to the baseline PDS. Eighty-five per cent of care was provided through approximately 10 items in the outsourcing funded models, compared to approximately 15 items in the PDS. The similarity of the overall items of care and the ranking (by volume) of items of care was similar among the three payment systems. Slight variations in ranks occurred between the three payment systems, as well as between respective practitioner types (Tables 1 ).

The major weakness of this study is the small number of children and adolescents who received dental care through the FFSS and CPS payment systems.
Nevertheless, this study has important implications for public dental services as it outlines alternative payment systems for the delivery of public dental care at a times when Commonwealth funding is available and the PDS alone cannot meet the demand for public dental services. In addition, the recent interest by the Australian Government's Productivity Commission in giving patients greater choice and greater use of the private sector also supports the further refinement of alternative payment systems for public dental services.

\section{CONCLUSION}

There was little difference in the mix of items of care provided between study years and age groups of the three payment systems (Figure 1). The differences between the PDS and those of the FFSS and CPS were minor. In both years, preventive dental care was the highest, providing over $50 \%$ of all groups of items of care in all payment systems. The most common preventive care between the three practitioner types (dentist, oral health therapist and $3^{\text {rd }}$ year oral health therapist student) and their associated payment systems were the fluoride treatment, dietary advice, oral health education and fissure sealant items of care. 


\section{References}

1. Australian Bureau of Statistics 2011 Census Quick Stats All people - usual residents. http://www.censusdata.abs.gov.au/census se rvices/getproduct/census/2011/quickstat (Accessed March 30, 2016)

2. Centre for Oral Health Strategy NSW. (2013). Oral Health 2020: A Strategic Framework for Dental Health in NSW. Ministry of Health, New South Wales, Australia 2-23.

3. Australian Institute of Health and Welfare. (2011). Dental workforce 2011. National Health Workforce Series 4. Australian Government 1-120.

4. Andersen LB, Bech M, Lauridsen J. (2013): Political or dental power in private and public service provision: a study of municipal expenditures for child dental care. Health Econ Policy Law 7, 327-342.

5. Centre for Oral Health Strategy NSW. (2008). Priority Oral Health Program and List Management Protocols PD2008_056. NSW Department of Health, Australia.

6. Centre for Oral Health Strategy NSW. (2016) Oral Health Fee for Service Scheme PD2016_018. Ministry of Health, New South Wales, Australia

7. Australian Government. (2011). Schedule of fees for Dentist, Specialists and Dental Prosthetists. Department of Veteran Affairs, Canberra Australia.

8. Conquest J, Jacobi M, Skinner J, Tennant M. (2014). Design of an innovative paediatric capitation payment approach for public sector dentistry: an Australian experience. Int Dent J 65, 32-38.

9. Centre for Oral Health Strategy NSW. (2009). The New South Wales Child Dental Health Survey 2007. Nth Sydney: NSW Department of Health, 14-30.
10. Australian Dental Association Inc (2009). The Australian Schedule of Dental Services and Glossary 9th Ed. Australian Dental Association Inc 1-48.

11. Birch S. (1989). Charges to patients impair the quality of dental care for elderly people. Age Aging 18, 136-140.

12. Atchison K, Schoen M: (1990). A Comparison of Quality in a dual-choice Dental Plan: Capitation versus Fee-for-service. JPHD 50,186-193.

13. Gosden $T$, Forland F, Kristiansenz IS, Sutton $M$, Lesse B, Giuffrida A, Sergison M, Pedersen L. (2001). Impact of payment method on behaviour of primary care physicians: a systematic review. J Health Serv Res Policy 6, 44-55.

14. Bradson J, Noskin D, Ruesch M. (1998) Differences in Practice Characteristics of Capitation and Pro Provider Dentists. J Am Dent Assoc; 129:208-222.

15. Lo E, Yeung J, Chu C. 2002) Fee-paying systems and service patterns in a Hong Kong clinic. Int Dent J. 52:261-267.

16. Andås CA., Hakeberg M. (2016) Payment Systems and oral health in Swedish dental care: Observations over 6 years. Community Dent Health 33, 257-261

17. Holloway P, Blinkhorn A, Hassell D, Mellor A, Worthington H. (1997) An assessment of capitation in the General Dental Service Contract 1 . The level of caries and its treatment in regularly attending children and adolescents. Br Dent.182:418-423. 